\title{
Curcumin/Green Tea Extract/Polygonum cuspidatum Extract/Soybean Extract Capsule
}

National Cancer Institute

\section{Source}

National Cancer Institute. Curcumin/Green Tea Extract/Polygonum cuspidatum

Extract/Soybean Extract Capsule. NCI Thesaurus. Code C78849.

An oral capsule containing curcumin, green tea extract, Polygonum cuspidatum extract, and soybean extract, with antioxidant and potential chemopreventive activities. The antioxidants in curcumin/green tea extract/Polygonum cuspidatum extract/soybean extract capsule bind to and neutralize free-radicals, which may prevent their genotoxic and carcinogenic effects. 